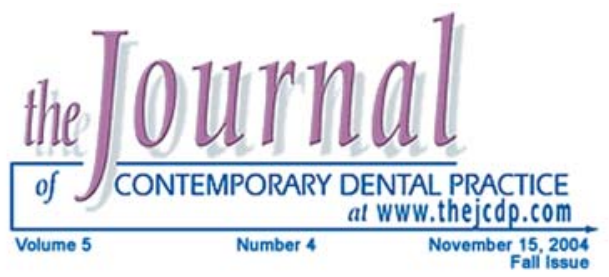

\title{
The Evolving Imapact of Aging America on Dental Practice
}

Kenneth Shay, DDS, MS

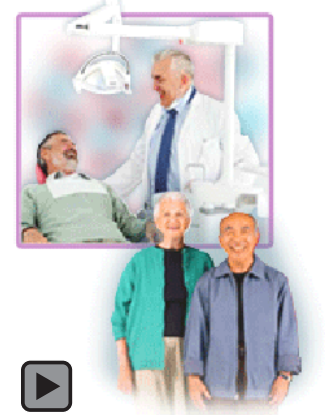

Abstract

American dentistry has recognized for a quarter century that the growth in the proportion of elderly in the population is impacting on the profession. Multiple articles in the professional literature have speculated on the ways in which this change will be manifested. Data and projections from earlier articles are revisited and five trends are offered to guide professionals as they position their practices for the coming years. The increase in number and proportion of elderly in dental practices stems from successes in preventing and controlling infectious diseases during the last century. The trend has not peaked but will continue for at least two more decades. Retention of teeth into advanced age has resulted from emerging and improved preventive and restorative dental advances directed at children and adults beginning mid-century, and dental utilization studies confirm the elderly are seeking dental care at an unprecedented and growing rate. Chronic disease and infirmity that accompany advanced age make dental care more challenging for this group. Dentists and their staff will need to continuously undertake educational opportunities that will foster and maintain their facility in providing care to the elderly. They will need to do this because Americans of advanced age are becoming the dominant age group seeking, and able to pay for, sophisticated dental services. The blend of those services is shifting away from removable prostheses to a rising demand for restorative, periodontic, and endodontic care. Root caries, in particular, will be a growing challenge to both providers and patients. There is mounting evidence oral disease impacts endocrine, cardiovascular, and pulmonary health, particularly in frail elders, and will likely provide many elderly additional stimuli to seek dental care. Providers who seek an alternative approach for delivering their services will find growing demand for and satisfaction with traveling to patients, rather than the other way around.

Keywords: Aging, dental care, dentistry

Citation: Shay K. The Evolving Impact of Aging America on Dental Practice. J Contemp Dent Pract 2004 November;(5)4:101-110.

(c) Seer Publishing 
Introduction

For over a quarter century dentistry has been noticing the growing proportion of adults living into their seventh decade and beyond is driving change within the profession. Qualitative and quantitative forecasts have examined parameters characterizing the profession and those it serves and have (1) speculated on how those factors may be influenced by age demographics, (2) predicted likely impact of those changes; and suggested recommendations to foster favorable outcomes and mitigate undesirable ones. ${ }^{1,2,3}$ Parameters examined have included background, age, and distribution of dental professionals; age, health, motivations, finances, and functional characteristics of present and future elderly populations; changes in dental disease and behaviors; and general societal trends. The scale and significance of recommendations flowing from projections have varied widely, covering "macro" issues (e.g., dental/ dental auxiliary workforce ${ }^{4,5}$, public and corporate reimbursement models ${ }^{6}$, curriculum change ${ }^{7}$, research foci ${ }^{8}$, alternative sites for care $^{3}$ ), "micro" issues (e.g., specific techniques/materials ${ }^{9}$, impact of medical conditions on care ${ }^{10}$ ), and those in between (e.g., office design ${ }^{11}$, standards of care $^{12}$ ).

This article will draw on a variety of these syntheses to advance five predictions on ways the growing number of older Americans will impact dental practice during the next two decades. Predictions are offered with the intention that providers should weigh them now to discern how to position themselves and their practices in a manner that will best serve the needs of their older patients in coming years.

\section{Prediction \#1: The proportion of the dental} population composed of older patients will continue to grow.

In 1900 about $3 \%$ of the US population--little more than 3 million Americans--were age 65 years or older. A century later, nearly $13 \%$ of the population--about 36 million--are in this age group. It is projected the elderly will make up $20 \%$ of the US population by 2030 . $^{13}$ This popu-

\section{Percentage of U.S. popluation over the age of 65}
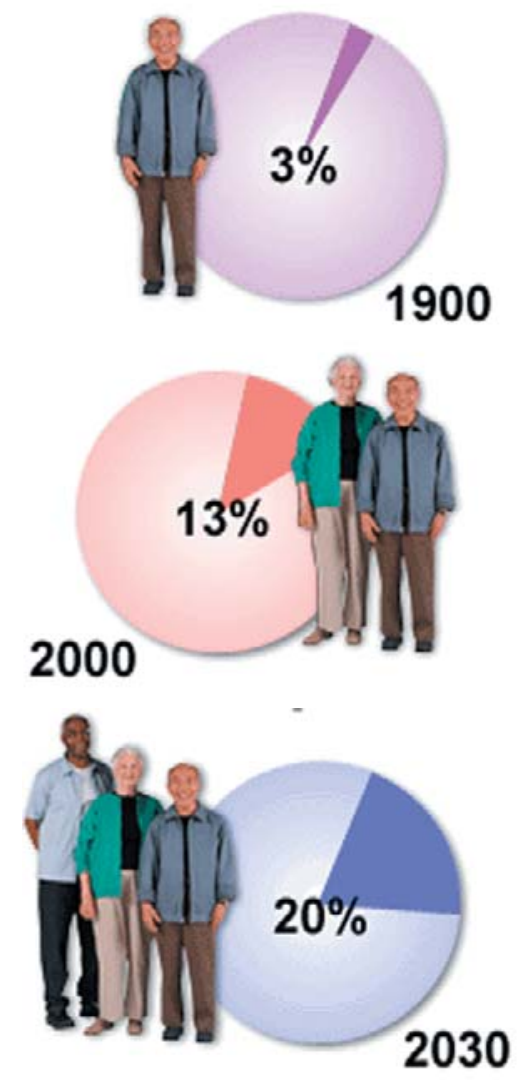

lation change makes unsurprising corresponding adjustments in dental practices' patient age mix, yet full appreciation of this change requires explanation of its origin. Put simply, during the twentieth century there was a dramatic decrease in the death rates of children, and to a lesser extent, of teens and adults. Twenty percent of children born in 1900 died before their fifth birthday. Today, fewer than $1 \%$ of American children die before they turn five; child mortality began dropping after the turn of the century when water purification and sewage treatment became widespread. Prior to the introduction of antibiotics mid-century, most child and adult deaths were due to infectious diseases. Effective infection prevention and management allowed unprecedented numbers to reach their fifties, sixties, and beyond. While growth in the elderly was relatively modest in the first half of the century, the trend accelerated in the 1960s and 1970s when impact of increased survival at all ages first had its full effect. Declining birth rate has also contributed to the growing proportion of elders. ${ }^{14}$ 
Increased numbers of older persons would not, by itself, translate into more older persons in dental practices unless people of all ages experience equivalent dental care needs. That equivalency was not true a half century ago, when over two-thirds of Americans 75 and older had no teeth. ${ }^{15}$ The high rate of edentulousness in advanced age caused a distinct drop-off in dental care utilization over age 50 . But fluoridation of drinking water and the introduction of dentifrice in the 1950s and growth and enhanced sophistication of the dental profession in the 1960s, resulted in vastly improved dental health in all age groups by the 1970 s and 80 s. $^{1}$ Today fewer than one third of Americans over age 75 are edentulous. ${ }^{16}$ Just as increased survival of younger people created an explosion in the number of seniors one or two generations later, increased disease resistance and preservation of teeth mid-century has meant the expanding population of Americans over age 65 have retained more teeth into advanced age than prior generations.

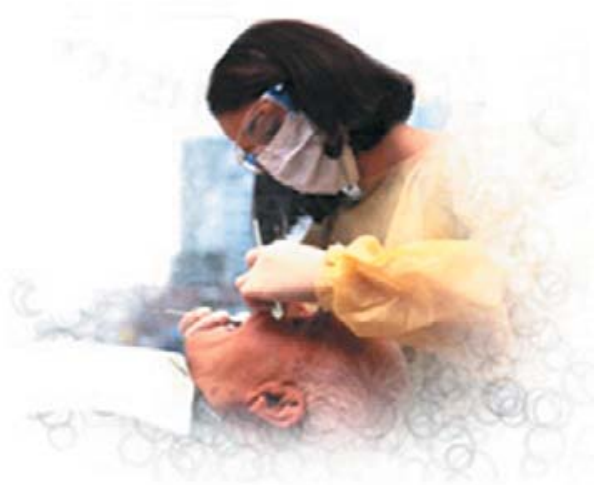

Dental literature confirms the growing tendency for older Americans to seek dental services. In 1979, Gift and Mankowski reported a 1978 nationally representative mail survey demonstrated that $56 \%$ of adults under age 65 sought dental care the preceding year, while only $30 \%$ of those over age $65 \mathrm{did}^{17}$ When these findings are combined with US Census figures, it can be derived that approximately $6.0 \%$ of dental visits were made by persons in the older age group. In contrast Meskin et al. ${ }^{18}$ reported in 1990 the proportion of older patients in a representative sample of practices in three of five states studied exceeded their proportion in each state's population (between $9.8 \%$ and $17.6 \%$ in the states studied). In a 2000 follow-up, the proportion of those practices composed of older patients exceeded the proportion of elderly in all five states. ${ }^{19}$

\section{Prediction \#2: Dentists and staff must become} comfortable delivering top-quality care that is integrated with patients' medical regimens and functional limitations.

Reduction of premature death has most affected the number of Americans surviving into their eighties and beyond. While those over age 65 have increased by a factor of over twelve since 1900, the number over age 85 has increased by over 22, representing over 4 million Americans. With increasing age comes increasing debility, as aggregate impact of nonfatal but irreversible disease processes and environmental effects accumulated through life--such as arthritis, atherosclerosis, pulmonary debris-takes its toll. ${ }^{14}$

\section{Accumulated chronic disease effects self- care: nearly $45 \%$ of per- sons over age 85 require assistance in one or more "activities of daily living," (bathing, dressing, toilet- ing, transferring, feed- ing $)^{20}$; oral care is likely affected in at least as many cases. ${ }^{21}$ As more}

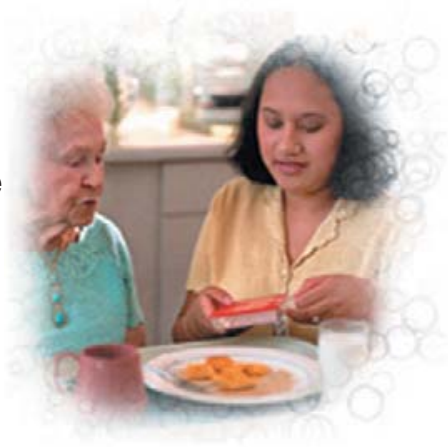
of these individuals have preserved their natural teeth, late-life increases in oral disease have resulted. ${ }^{22}$ But often the same chronic illnesses that contributed to compromised self care, make dental professionals uncomfortable and/or reluctant to treat these patients. ${ }^{23}$

When dental care for an older person was a relative rarity--not a prominent part of a practice's revenue stream--arbitrarily postponing care for six months after a stroke, or under treating someone 
with a cardiac condition out of concern over a potential emergency situation, was common-sense risk management. Today the regularity with which older patients report complex, chronic medical conditions means that dental practices must have the necessary skills, knowledge, and confidence to correctly manage older patients' dental health needs despite concurrent medical challenges.

Continuous education of providers and staff and efficient, effective means for obtaining expert consultation on medical, behavioral, functional, and pharmacological characteristics impacting the provision of dental care are key to successful, profitable dental management of older patients. Dental providers need to consciously work to develop and maintain interdisciplinary relationships--e.g., with physicians, nurses, therapists, social workers--who can help integrate planned dental treatment with diagnostic, therapeutic, and social support complexities of geriatric care. Dentists need to keep abreast of technological advances to assist them and their staffs in accessing, understanding, and organizing information about their patients' diagnoses and therapies.

\section{Prediction \#3: Older patients will account for} a growing proportion of practice income. The proportion of Americans over age 65 is rising, as is the proportion of dental patients in this age group. Yet those two facts alone do not support a recommendation that practices should cater to the group's needs. The dental profession serves all society, but a dental practice is expensive to establish and maintain; survival relies on identifying markets that are more profitable in order to support care for the less profitable but needy. The question is, in which market do the elderly belong?

There is validity to the image of the impoverished older person. Millions of American elderly, particularly minorities and women, live at or near poverty level. The aged poor account for the majority of Medicaid's hundred-plus billion dollar annual expenditures. ${ }^{2} 4$ This population is caught in a downward spiral of rising drugs costs, an increasing need for medical care, a fixed income, and dwindling assets. Yet "the elderly" also include millions of comfortably affluent retirees. $^{25}$ Industry-funded retirement pensions proliferated after World War II on top of a thriftiness ethic cultivated in the Depression, raising the present generation of elderly to unprecedented levels of relative affluence.1 Over 65\% of discretionary wealth in the country belongs to Americans over age $50 .^{26}$ Thus, while large numbers of elders endure a subsistence existence, greater numbers control assets that permits them a comfortable lifestyle and freedom expending their resources.

Dental spending by the elderly mirrors the observation of older Americans' resources. Meskin at al. reported in $1990^{18}$ dental expenditures by those over age 65 in three of five states studied represented a proportion of dental practice income greater than the proportion of the practice population made up by those patients. The same authors repeated their investigation a decade later $^{19}$ and found the elderly's contribution to practice incomes had continued to grow and now exceeded practice proportion in all five states. Any growing group that also accounts for a disproportionate share of practice income merits careful consideration as a business target.

Dental practices will need to pay attention to these trends when locating and outfitting offices. When preventive dental care was gaining a foothold in the 1960s, ideal locations were in suburban locales, near schools and young families that would guarantee steady patient supply. With the dramatic decline in pediatric dental disease, it is a safer investment to locate near large concentrations of affluent retirees. Offices need to be sensitive to preferences of this age group, offering earlier hours, convenient parking, access to public transportation, brighter lighting, and wheelchair access. 
Prediction \#4: Provision of removable appliances will continue to give way to increasing demand for restorative and preventive services.

Although the percent of Americans over age 75 who are edentulous has dropped since the 1950 's, an explosion in the number of persons in this age group and their lengthening life span has continued to result in increased numbers of very old who are without teeth. ${ }^{27}$ This trend will soon slow and then stop as more individuals who retained their teeth at younger ages begin their eighth decade. Further, many edentulous elderly have been without teeth for decades and seek complete denture services only infrequently. ${ }^{28}$ Total tooth loss in adults in their thirties and forties has become uncommon, so despite increasing numbers of elderly edentulous adults, most dental students acquire very limited experience in providing complete denture treatment compared to their predecessors. As a result, traditional denture service is increasingly referred to prosthodontists and/or played down in favor of implant-related care, or is self-referred to less costly sources.

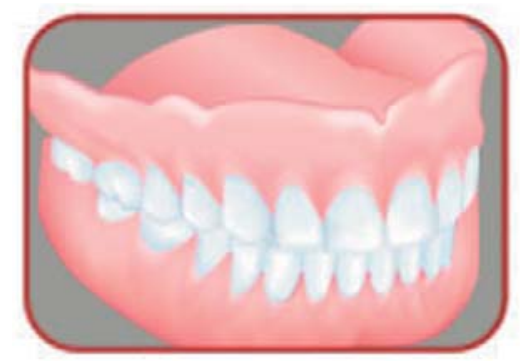

Most older dental patients seek services for maintaining dentitions: restorative, preventive, and periodontic services. ${ }^{29}$ Dentate older adults were not exposed to fluoride until later in life and, therefore, have experienced significant earlier restorative care earlier in life. Restorative needs in seniority are typically more extensive, and more likely to necessitate extracoronal coverage and consideration for endodontics.

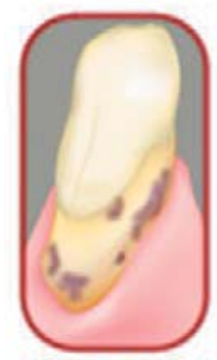

A lifetime's exposure to localized, time-limited but additive episodes of osteoclastic activation in response to periodontal pathogens and variations in host resistance, results in the nearly universal finding of measurable, whole-mouth alveolar bone loss in Americans over age $50 .{ }^{30}$ Once Root Caries root surfaces become supragingival, they become prone

to decalcification. ${ }^{9}$ Root caries is rare before middle adulthood, but becomes common with advancing age. Both dental personnel and patients are frustrated by root caries, as traditional operative preparations and materials commonly fall short of expectations. Dentists and staff need to realize the unfavorable oral equilibrium represented by root caries is only managed in part by restoration. Aggressive preventive care, including home fluoride and dietary counseling, are required if root caries is to be managed successfully.

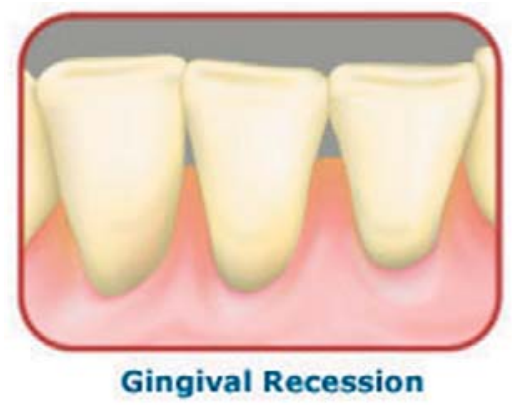

Gingival recession and other manifestations of prior periodontal disease drive ongoing need for regular dental prophylaxis in advanced age. The current emphasis on prevention in American consciousness ${ }^{31}$ spills over into oral health; older patients who have maintained their teeth beyond expectations of prior generations recognize as never before that regular checkups and cleanings are necessary for keeping their smiles healthy.

This prediction for growing demand for complex restorative and preventive/periodontal maintenance care is not mere speculation. Meskin and others found removable prosthodontic services for older adults diminished as a percent of practice income from 1990 to $2000^{18,19}$, even as income from endodontic and periodontic services rose in the same period. Eklund analyzed fifteen years' experience of several dental insurance plans, representing the experiences of over 750,000 patients, and noted demand for operative and prosthodontic services dropped in all age groups except those over age 65--for whom demand of these services increased--over the fifteen years during the period $1980-1995 .^{32}$ 
Prediction \# 5: The dental demands of the elderly will affect all parts of the dental marketplace.

In 1995 Strauss and Hand explored motivations for seeking dental care among older adults. ${ }^{33}$ They found the elderly, as a group, seek care for reasons similar to younger groups: pain-free oral function and a nice appearance. Subjects in the study also reported a third motivator: health and well-being. This last

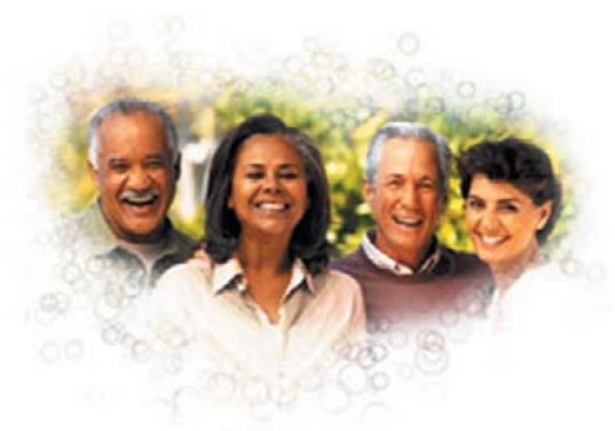

factor raises some closing predictions.

The barrage of attractive smiles in the media constantly confronting every American has markedly altered what people of all ages will tolerate in their own appearance. Tremendous improvements in facial esthetics are possible through orthodontics, pedicle-flap root coverage, porcelain veneers, and vital bleaching. People who have denied their own needs through child-rearing and college-supporting years will be increasingly interested in treating themselves to a "dental makeover" well into their seventh decade and beyond.

That older individuals see oral health as part of their overall health suggests this group will have a strong interest in the growing body of evidence linking systemic and oral health. Patients' tendencies to want to preserve their dental health are strengthened by evidence linking diabetes and periodontal disease ${ }^{34}$, oral health and pneumonia $^{35}$, and oral inflammation and atherosclerot- ic disease. ${ }^{36}$ Dentists will need to be conversant on these topics as patients will want to explore more fully the evidence and often misrepresented correlations that appear in the media.

A final prediction applies not to every provider but to those who are particularly motivated to manage frail patients' care. Even as the number of American elders has grown sharply, the number of US nursing home beds has remained relatively stable..$^{37}$ Growing numbers of older persons with chronic disabilities prefer to remain in their communities $^{38}$, either in their homes or in less restrictive congregate housing settings ("assisted living"). Many manage to arrange transportation to and from the dental practice, but others are unable to do so. In geriatric medicine, growing numbers of physicians are opting for the improved professional satisfaction of house calls as the favorable trade-off for a more remunerative but more hectic lifestyle. ${ }^{39}$ In an entirely analogous manner growing numbers of dentists are finding-and even more will soon find--professional satisfaction in going to patients, rather than compelling patients to come to them. ${ }^{40}$

\section{Conclusion}

Dental care for older persons has become mainstream. The rising numbers of older patients, the extent of their dental care needs, their interests in care, and their ability to pay make them a market that dentistry must not regard as novel but recognize as crucial for practice survival. There are unfamiliar challenges faced when addressing the preventive and interventive aspects of care for frail older adults, but with ongoing training dental staff can not only grow comfortable with this patient group, they can provide appropriate and superior care to this segment of the population--and even enjoy doing so. 


\section{References}

1. Ettinger RL, Beck JD. The new elderly: what can the dental profession expect? Spec Care Dent. 1982; 2:62-9.

2. Dolan TA, Atchison KA. Implications of access, utilization and need for oral health care by the noninstitutionalized and institutionalized elderly on the dental delivery system. J Dent Educ. 1993; 57: 876-87.

3. Berkey DB, Berg RG, Ettinger RL, et. al. Research review of oral health status and service use among institutionalized older adults in the United States and Canada. Spec Care Dent. 1991; 11: $131-6$.

4. DiAngelis AJ, Smith BJ. Training tomorrow's leaders in oral health services for older adults. Gerodontics. 1985; 1:59-62.

5. Personnel for health needs of the elderly through year 2020. National Institute on Aging, 1987. NIH Publication no. 87-2950.

6. Meskin LH, Mason LD. Problems in oral health care financing for the elderly. Clin Geriatric Med. 1992; 8:685-92.

7. Beck JD, Block M, Gilmore ND, et. al. Curricular guidelines in geriatric dentistry. J Dent Educ. 1982; 46:346-9.

8. Baum B. Research on aging and oral health: an assessment of current status and future needs. Spec Care Dent. 1981; 1:156-65.

9. Shay K. Root caries in the older patient: significance, prevention, and treatment. Dent Clin N Amer. 1997; 41:763-93.

10. Ship JA. Oral sequelae of common geriatric diseases, disorders, and impairments. Clin Geriatr Med. 1992; 8:483-97.

11. Bomberg T, Ernst M. Improving the dental office environment for the older patient. J Am Dent Assoc. 1984; 108:789-91.

12. Shay K. Oral neglect in the institutionalized elderly: Part 2. The role of the dentist and the standard of care. Spec Care Dent. 1990; 10:200-3.

13. American Association of Retired Persons (AARP) and Administration on Aging (AOA), U.S. Department of Health and Human Services. "Profile of Older Americans". 1999.

14. Fries JF. Aging, natural death, and the compression of morbidity. N Eng J Med. 1980; 303:130-5.

15. Edentulous persons: United States-1971. Vital and health statistics series 10, no. 89. Department of Health, Education, and Welfare Publication no. (HRA) 74-1516, National Center for Health Statistics, 1974.

16. Miller AJ, Brunelle JA, Carlos JP, et. al. Oral health in United States adults. Washington, DC: national survey of oral health in US employed adults and seniors: 1985-86. US Department of Health and Human Services. NIH publication no. 87-2868, 1987.

17. Gift HC, Mankoski I. Utilization of Dental Services: 1978 National Public Survey. J Dent Res. 1979;58:132.

18. Meskin LH, Dillenberg J, Heft MW, et. al. Economic impact of dental service utilization by older adults. J Am Dent Assoc. 1990; 120:665-8.

19. Meskin L, Berg R. Impact of older adults on private dental practices, 1988-1998. J Am Dent Assoc. 2000; 131:1188-96.

20. National Center for Health Statistics. Health, United States, 1999 with Health and Aging chartbook. 1999. Hyattsville, MD: U.S. Department of Health and Human Services; National Center for Health Statistics. DHHS Pub. No. (PHS) 99-1232.

21. Shay K. Dental management considerations for institutionalized geriatric patients. J Prosthet Dent. 1994; 72:510-6.

22. Beck J, Hunt R, Hand J, et. al. Prevalence of root and coronal caries in a non-institutionalized older population. J Am Dent Assoc. 1985; 111:964-7.

23. Dolan TA, McNaughton CA, Davidson SN, et. al. Patient age and general dentists' treatment decisions. Spec Care Dent. 1992; 12:15-20.

24. Rowland D, Lyons B, Edwards J. Medicaid: health care for the poor in the Reagan era. Ann Rev 
Publ Health. 1988; 9:427-50.

25. Schneider EL, Guralnick JM. The aging of America: impact on health care costs. JAMA. 1990; 263: 2335-40.

26. Hobbs EB, Damon BL. Sixty-five plus in America. Current Population Reports, Special Studies P23-P190. 1996; Washington, D.C.: U.S. Department of Commerce; Economics and Statistics Administration; Bureau of the Census.

27. Shay K, Ship, JA. The importance of oral health in the older patient. J Amer Geriatr Soc. 1995; 43: 1414-22.

28. Douglass SW, Gammon MD, Atwood DA. Need and effective demand for prosthodontic treatment. J Prosthet Dent. 1988; 59:94-104.

29. McGuire SM, Fox CH, Douglass, et. al. Beneath the surface of coronal caries: primary decay, recurrent decay, and failed restorations in a population-based survey of New England elders. J Publ Health Dent. 1993; 53:76-82.

30. Burt BA. Periodontitis and aging: reviewing recent evidence. J Am Dent Assoc. 1994; 125:273-9.

31. Atchison KA, Mayer-Oakes SA, Schweitzer SO, et. al. The relationship between dental utilization and preventive participation among a well-elderly sample. J Publ Health Dent. 1993; 53:88-95.

32. Eklund SA, Pittman JL, Smith RC. Trends in dental care among insured Americans: 1980 to 1995. J Am Dent Assoc. 1997; 171-8.

33. Strauss RP, Hunt RJ. Understanding the value of teeth to older adults: influences on the quality of life. J Am Dent Assoc. 1993; 124:105-10.

34. Taylor GW. Periodontal treatment and its effects on glycemic control. Oral Surg Oral Med Oral Pathol Oral Radiol Endod. 1999; 87:311-6.

35. Scannapieco FA, Bush R, Paju S. Associations between periodontal disease and risk for nosocomial bacterial pneumonia and chronic obstructive pulmonary disease. A systematic review. Ann Periodontol. 2003; 8:54-69.

36. Hujoel PP, Drangsholt M, Spiekerman C, et. al. Examining the link between coronary heart disease and the elimination of chronic dental infections. J Am Dent Assoc. 2001;132:883-9.

37. Stone R. Long-term care for the disabled elderly: current policy, emerging trends and implications for the 21st century. A special electronic report of The Milbank Quarterly January 2000.

38. Citro J, Hermanson S, Consumer Team, Public Policy Institute Research Group. "Assisted Living in the United States". 1999; Washington D.C: American Association of Retired Persons (AARP).

39. Ettinger WH Jr. The Balanced Budget Act of 1997: implications for the practice of geriatric medicine. J Am Geriatr Soc. 1998; 46:530-3.

40. Henry RG, Ceridan B. Delivering dental care to nursing home and homebound patients. Dent Clin N Amer. 1994; 38:537-551.

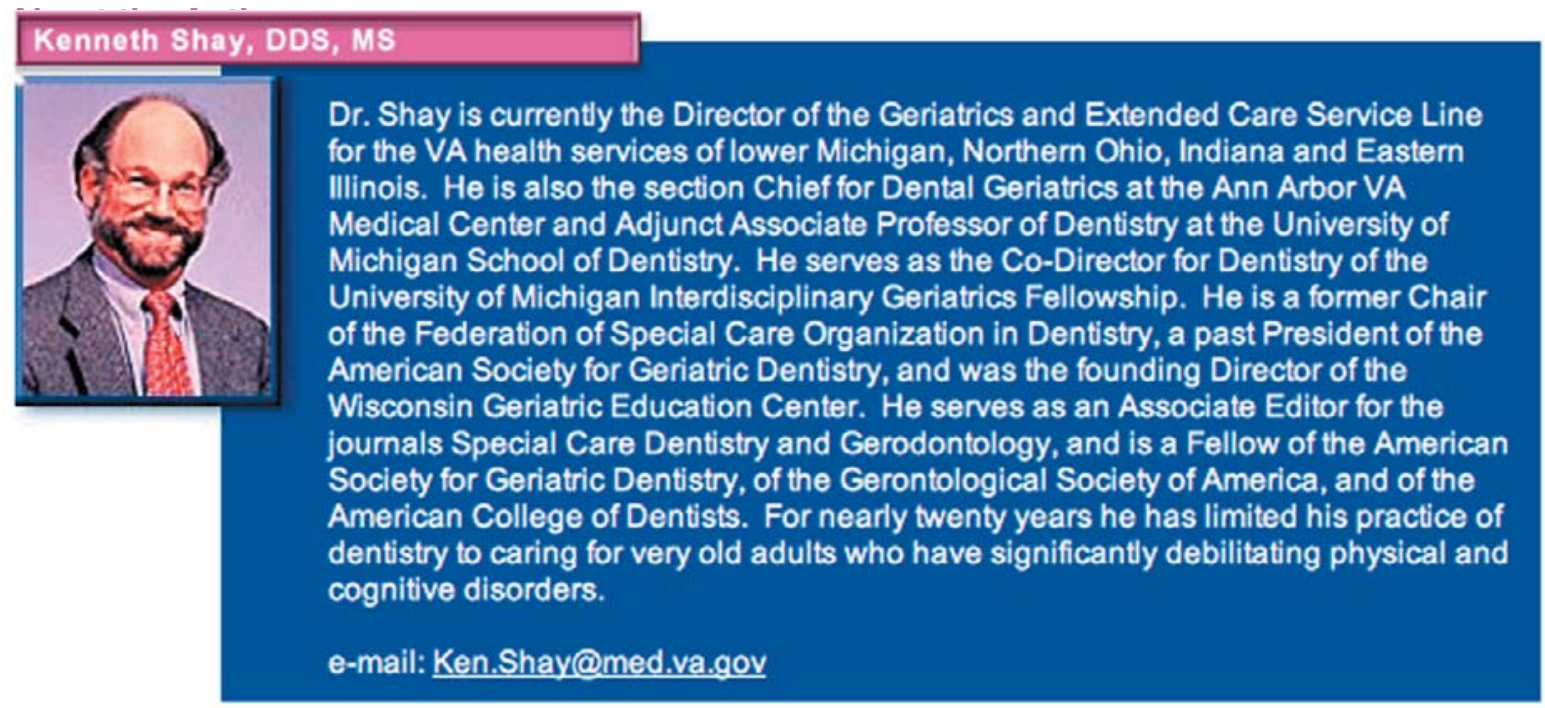

